\title{
In Vitro Antimalarial Activity of Extracts of Some Indigenous Plant Species in Kebbi
} State

\author{
${ }^{* 1}$ Aisha Abdulrazaq, ${ }^{2}$ Bashir Abdulkadi, ${ }^{3} \mathrm{~N}$. T. Isyaku, ${ }^{4}$ Musa Yahaya, ${ }^{5}$ Badru O. A., ${ }^{6}$ Lawal \\ Adamu and ${ }^{7}$ Alkali $\mathrm{K}$. \\ 1,3,4 Department of Microbiology, Kebbi state university of science and technology, Aleiro \\ 2 Department of Microbiology Umaru Musa Yaradua University, Katsina \\ 4 Department of Biochemistry, Kebbi state university of science and technology, Aleiro \\ 5 Department of Physiotherapy, Usman Dan Fodio University Teaching Hospital Sokoto \\ 6 Department of Microbiology, Federal University Birnin-Kebbi \\ 7Department of GST, Mohammed Goni College of legal and Islamic studies, Maiduguri \\ *Corresponding author e-mail: abdulrazaq.aishaaa@gmail.com
}

\begin{abstract}
The search for antimalarial compounds has been necessitated by the resistance of Plasmodium falciparum to almost all antimalarial drugs. The aim of this research was to determine in-vitro antimalarial activity of extracts of some indigenous plants species in Kebbi State. Plant extraction was carried-out by maceration using ethanol and water as solvent. The antiplasmodial activity of the extracts was evaluated against fresh clinical isolates of $P$. falciparum using WHO method of in-vitro micro test. Phytochemical screening was also carried out on the extract to deduce the active chemicals present in the plant extract. All plant extracts demonstrate dose dependent antimicrobial activities with IC50 Less than 50\%. However highest growth inhibition of the $P$. falciparum was demonstrated by aqueous and ethanol extract of $A$. indica with IC50 $7.4 \mu \mathrm{g} / \mathrm{ml}$ and $8.6 \mu \mathrm{g} / \mathrm{ml}$ respectively followed by ethanol and aqueous extract of C. occidentalis with IC50 $15.3 \mu \mathrm{g} / \mathrm{ml}$ and $18.0 \mu \mathrm{g} / \mathrm{ml}$ respectively. Least antimalarial activity was demonstrated by aqueous extract of $M$. oleifera with IC50 $33.5 \mu \mathrm{g} / \mathrm{ml}$ while ethanolic extract of $M$. oleifera demonstrated IC50 of $20.50 \mu \mathrm{g} / \mathrm{ml}$. M. indica ethanolic and aqueous extract also demonstrated moderate antimalarial activity with IC50 $18.8 \mu \mathrm{g} / \mathrm{ml}$ and $24.5 \mu \mathrm{g} / \mathrm{ml}$. The phytochemical screening of medicinal plants showed the presence of tannins, saponins, alkaloids, flavonoid, phenol and cardiac glycosides in the extracts, which may be responsible for the antiplasmodial activity. This result justifies the traditional use of the plant in malaria treatment and further research is suggested to identify and characterize the active principles from the plants.
\end{abstract}

Keywords: Antimalaria, Invitro, Medicinal Plants, Malaria, Kebbi

\section{INTRODUCTION}

Malaria is a disease is of global importance that results in 300-600 million cases annually and an estimated 2.2 billion people are at risk of infection according to Singh et al (2011). Despite more than a century after identification of the causative parasites and more than half a century of finding effective drugs and insecticides, the disease is still as deadly as ever (Mehta and Desai, 2013).

Malaria is caused by a parasite in the blood called Plasmodia. Five species (Plasmodium falciparum, $P$. vivax, $P$. ovale, $P$. malariae and $P$. knowlesi) of this genus are implicated in human malaria, with the most deadly to be Plasmodium falciparum. They are usually transmitted via the bite of infected female Anopheles mosquitoes
(Umar et al., 2017). Numerically the most important of the life threatening protozoan disease is malaria, which is responsible for at least 750,000 death a year, mostly in young children in Africa (Greenwoodv et al., 2012; WHO, 2015). Clinical symptoms of malaria ranges from acute febrile illness with fever associated with chills, headache, and vomiting to deadly complications like severe anaemia, respiratory distress in relation to metabolic acidosis, or cerebral malaria which can eventually lead to death (Singh, 2011).

Transmission of the disease occur all year round in the Southern part of the country while in the Northern part, the disease is more seasonal, killing children every 30 seconds, hence, pregnant women and their unborn children 
UJMR, Volume 5 Number 2, December, 2020, pp 1 - 10 ISSN: 2616 - 0668

become vulnerable to malaria which serves as the major cause of maternal anemia, low birth weight and increase in child mortality (Liadi et al., 2016). Over half of the world's population is at risk from catching malaria. Malaria is currently endemic in 109 countries in four continents and of the 500 million cases of malaria estimated to occur annually, approximately one million result in death. Most of the fatalities are in children under the age of five years old and pregnant women(Lamb, 2012). Africa accounts for $91 \%$ of all malaria deaths and, with an estimated 57.5 million cases and 225,000 deaths per year. Nigeria accounts for $27 \%$ of the total African malaria burden (WHO, 2017). There are estimated 100 million cases of malaria with over 300,000 deaths and $50 \%$ of the population has at least one episode of malaria every year $(\mathrm{FMOH}$, 2015). Within Nigeria, malaria is a major cause of illness, death, and poverty, and a significant drain on the economy and wellbeing of the nation. It is estimated that $50 \%$ of Nigeria's adult population will have at least one episode of malaria each year and children under five will have 2-4 attacks annually (Oladepo et al., 2019). The nation loses over 132 billion naira annually in form of treatment costs, prevention, loss of man-hours etc. (FMOH, 2015; Uzochukwu and Emma-ukaegbu, 2010). Children under five and pregnant women are most at risk for malariarelated morbidity and mortality, with $11 \%$ of maternal and $20 \%$ of under-five deaths attributed to malaria (NMEP, 2016). Poorer and more rural populations are also at greater risk, with malaria prevalence higher among the lowest wealth quintile and among rural populations (Oladepo et al., 2019).

\section{MATERIALS AND METHODS \\ Ethical Consideration}

The study was approved by Kebbi State Ministry of Health with ethical letter reference $\mathrm{MOH} / \mathrm{KSREC} / \mathrm{VOL} . \mathrm{I} / 56$.

\section{Plant identification}

The plant sample was collected fresh from various communities in the study area with the help of informants who participated in the survey carried out and authenticated by Plant Taxonomist at Herbarium of Kebbi State University of Science and Technology, Aleiro where voucher numbers were obtained.

\section{Plant Sample Collection}

Most frequently mentioned plants from survey result were selected to determine the antimalarial potentials of the plant extract. Selected plants are: Cassia occedentalis,
Azadirachta indica, Moringa oleifera and Magnifera indica. The plant sample already collected and identified in Herbarium Unit was used.

\section{Extraction}

Fresh leafs of the selected plant was obtained. The leaves were washed and air dried at room temperature. The extraction was performed by maceration process. This involved soaking $100 \mathrm{~g}$ of the crude powder of the plant in each of $1000 \mathrm{mls}$ of aqueous and ethanol, covered with intermittent shaking for 72 hours. The resultant extract was filtered using muslin cloth and number one Whatman filter paper. The extract was concentrated using pressured controlled rotary evaporator at $40^{\circ} \mathrm{C}$. The percentage yield of all the crude extracts were determined as percentage of weight $(\mathrm{g})$ of the extract to the original weight $(\mathrm{g})$ of the dried sample used(Umar et al., 2017).

\section{Phytochemical Test}

Phytochemical screening was carried out on the extract to detect the presence of tannins, saponins, alkaloids, flavonoid, phenol and cardiac glycosides in the plant extract. These tests were carried out using standard procedures to as described by Sofowora(1993) and Trease and Evans (1989).

Tests for Tannins

$0.5 \mathrm{ml}$ of the extract was put in a test tube and a few drops of $0.1 \%$ ferric chloride were added and the mixture was observed for brownish green or blue black colouration.

\section{Test for Alkaloids}

$0.5 \mathrm{ml}$ of the extract was stirred in $5 \mathrm{ml}$ of $1 \% \mathrm{HCl}$ on a steam bath for 5 minutes. The mixture was filtered using Whatman's filter. To the filtrate, 24 drops of Dragendoff's reagent was added to $1 \mathrm{ml}$ of the filtrate. An orange colouration indicated the presence of alkaloids.

\section{Test for Flavonoids}

$1 \mathrm{ml}$ of the extract was heated with $10 \mathrm{ml}$ of ethyl acetate over a steam bath for 3 minutes. The mixture was filtered and $4 \mathrm{ml}$ of the filtrate was shaken with $1 \mathrm{ml}$ of the dilute ammonia solution. A yellow colouration indicated the presence of flavonoids.

Test for Cardiac Glycosides (Keller-Killani test). $0.5 \mathrm{ml}$ of the extract was treated with $2 \mathrm{ml}$ of glacial acetic acid containing one drop of ferric chloride solution. It was under laid with $1 \mathrm{ml}$ of concentrated $\mathrm{H}_{2} \mathrm{SO}_{4}$. A brown ring at the interface indicated deoxysugar characteristics of cardenolides. A violet ring may appear below the brown ring, while in the acetate acid layer, a 
UJMR, Volume 5 Number 2, December, 2020, pp 1 - 10

ISSN: 2616 - 0668

greenish ring may form just gradually throughout

Test for Saponin

$10 \mathrm{ml}$ of distilled water was added to $0.5 \mathrm{ml}$ of

each extract in a test tube. It was shaken vigorously for 2 minutes. The presence of fronting or bubbling indicated the presence of saponin.

Test for Phenol

A small amount of the extract was taken with 1 $\mathrm{mL}$ of water in a test tube and 1 to 2 drops of Iron III chloride $\left(\mathrm{FeCl}_{3}\right)$ was added. A blue, green, red or purple color is a positive test

\section{Antimalarial Assay}

Preparation of Culture Medium for Cultivation of Plasmodium falciparum

The cultivation of the plasmodium parasite was carried out using the technic described by Trager and Jensen (1976) in which one packet of Rosewell Memorial Park Institute (RPMI) 1640 medium (containing $25 \mathrm{mM}$ of HEPES buffer, glucose) was dissolved in $960 \mathrm{ml}$ of double distilled water into which $40 \mu \mathrm{g} / \mathrm{ml}$ of gentamycin sulfate $(1.2 \mathrm{ml}$ of Gentamycin/L) was added. This solution was passed through a Millipore filter of $0.22 \mu \mathrm{m}$ porosity and store at $4^{\circ} \mathrm{C}$ as $96 \mathrm{ml}$ aliquots in glass media bottle. Exactly $4.2 \mathrm{ml}$ of $5 \%$ sodium bicarbonate $(5 \mathrm{gms}$ of sodium bicarbonate dissolved in $100 \mathrm{ml}$ double distilled water and filtered through a Millipore filter of $0.22 \mu \mathrm{m}$ porosity and store at $4^{\circ} \mathrm{C}$ ) was added to $96 \mathrm{ml}$ of stock RPMl 1640 media (Incomplete media).

O+ blood was collected in centrifuge tube without anticoagulant and kept at $4^{\circ} \mathrm{C}$. It was centrifuged at $10000 \mathrm{x} \mathrm{g}$ for $20 \mathrm{~min}$ at $4^{\circ} \mathrm{C}$ next day. Serum collected was separated aseptically and kept in aliquots. The serum was inactivated by keeping using water bath at $56^{\circ} \mathrm{C}$ for half an hour. Normal inactivated $\mathrm{O}+$ human serum (10 $\mathrm{ml}$ ) was added to $90 \mathrm{ml}$ of incomplete media to make complete malaria media(CMM).

\section{In-vitro Cultivation of P.falciparum}

Suspension of (50\% hematocrit) un-infected cells with CMM (with $15 \%$ serum) was prepared. Appropriate amount of uninfected cells was added to an initial $0.75 \%$ of parasitaemia and diluted with CMM to get $0.5 \%$ cell suspension ( $5 \%$ hematocrit). The culture was kept in a candle jar in an atmosphere of $\mathrm{CO}_{2}$ at $37^{\circ} \mathrm{C}$ for 48 hours. After every 48 hours the media was removed using a sterile Pasteur pipette without disturbing the cells that settled down. Then the cells mixed without frothing and a drop of blood was placed on the slide to make a thin film. The prepared thin film was stained and examined for parasitaemia.

UMYU Journal of Microbiology Research thin layer.

In-vitro Anti-plasmodial Activity of the Plant

\section{Extracts}

The assay was performed in triplicate in a 96-well microtiter plate, according to WHO method [in vitro micro test (Mark III)] by assessing the inhibition of schizont maturation (WHO, 2001). RPMI 1640 (Sigma Company, USA) was incorporated. Dilution was prepared from the crude plant extract at concentrations 100, 50, $25,12.5,6.25,3.13 \mu \mathrm{g} / \mathrm{ml}$ with DMSO and use to pre-dose the micro-titer plate. Negative control treated with solvent and positive control (Chloroquine phosphate) was added to each set of experiments. Two hundred microliters from blood mixture with media was added to each well in plate and incubated in $\mathrm{CO} 2$ condition at $37^{\circ} \mathrm{C}$ for $30-40$ hours. The contents of the wells were harvested smear on slides and stained for $30 \mathrm{~min}$ in a $2 \%$ Giemsa solution at $\mathrm{pH} 7.2$, after which the developed schizonts with three or more nuclei per 200 asexual parasites were counted in triplicate. The control and the test wells were compared for the determination of the percentage inhibition. The inhibitions of parasite growth in the drug treated groups were calculated as follows:

Percentage inhibition $=$

100 - Number of schizonts in test well $\times 100$

Number of schizonts in control wells

\section{Statistical analysis}

The anti-plasmodial activities of the extracts were expressed by the concentrations of the drug that inhibited $50 \%$ parasites (IC50) relative to the negative control. These IC50 values were calculated by plotting the inhibition (\%) against the logarithm to the base 10 of the concentrations of the extracts $(\log 10$ concentration) using regression equation $(\mathrm{y}=$ $\operatorname{aLn}(x)-c)$ where $y=$ percentage inhibition, $\operatorname{Ln} x=$ anti-log of concentration of extract, $a=$ slope, $c=$ constant. ANOVA test was used to compare means of plant extracts with $p$-value $\leq 0.05$ considered significant.

\section{RESULTS}

Antimalarial Activity

The results of the antimalarial activity of Azadirachta indica, Cassia occidentalis, Moringa Oleifera and Mangifera indica on the schizonts growth of $P$. falciparum are presented in Table 1. All plant extracts demonstrated varying antimalarial activity with different parasite count and percentage inhibition as compared with the positive and negative controls. 
UJMR, Volume 5 Number 2, December, 2020, pp 1 - 10

ISSN: 2616 - 0668

The highest level of parasite inhibition was observed with Azadirachta indica and Cassia occidentalis. Azadirachta indica inhibited 100\% both aqueous and ethanolic extract with $100 \mu \mathrm{g} / \mathrm{ml}$. Cassia occidentalis inhibited $99 \%$ ethanolic extract and 98\% aqueous extracts with $100 \mu \mathrm{g} / \mathrm{ml}$. Mangifera indica Ethanol and Aqueous extract inhibited the growth of $P$. falciparum by $89.86 \%$ and 81.30 respectively when treated with $100 \mu \mathrm{g} / \mathrm{ml}$. M. indica and M. oleifera show lowest antimicrobial activity among all the plant extract with percentage inhibition of $2.7 \%$ and $6.6 \%$ respectively at the lowest concentration of $3.13 \mu \mathrm{g} / \mathrm{ml}$.

The result of the anti-plasmodial activity of each plant extracts at different concentrations is shown in Figure 1 to 4 which shows higher activity in ethanol extract at all the 6 different concentrations except for Azadirachta indica in which the aqueous extract shows more inhibition than ethanolic extract. Azadirachta indica aqueous, ethanol extract and Cassia occidentalis ethanolic extract showed no significant difference at $(\mathrm{P}<0.05)$ in the anti- plasmodial activity when compared to positive control. Other plant extract showed slight to large significant difference in the anti- plasmodial activity compared to positive control.

In Figure 5, 1C50 value which is the concentration require to inhibit 50\% of the parasite show that the aqueous extract of Azadirachta indica has the lowest 1C50 of $7.39 \mu \mathrm{g} / \mathrm{ml}$ which made it the most potent among the 8 extracts and Moringa oleifera aqueous extract with the highest 1 C50 of $33.54 \mu \mathrm{g} / \mathrm{ml}$ is the least potent.

Phytochemical Screening

Qualitative phytochemical investigation of aqueous and ethanolic leaf extracts of Azadirachta indica, Cassia occidentalis, Moringa Oleifera and Mangifera indica are presented in Table 5. The result revealed the presence of alkaloids, cardiac glucosides, flavonoids, saponins and tannins in both aqueous and ethanolic leaf extracts. 
UJMR, Volume 5 Number 2, December, 2020, pp 1 - $10 \quad$ ISSN: 2616 - 0668

Table 1: Antimalarial activity of plant extracts

\begin{tabular}{|c|c|c|c|c|c|c|c|c|c|c|c|c|}
\hline \multirow[t]{3}{*}{ Extract } & \multicolumn{12}{|c|}{ Concentration (mean \pm SD) } \\
\hline & \multicolumn{2}{|c|}{$3.13(\mu \mathrm{g} / \mathrm{ml})$} & \multicolumn{2}{|c|}{$6.25(\mu \mathrm{g} / \mathrm{ml})$} & \multicolumn{2}{|c|}{$12.5(\mu \mathrm{g} / \mathrm{ml})$} & \multicolumn{2}{|c|}{$25.0(\mu \mathrm{g} / \mathrm{ml})$} & \multicolumn{2}{|c|}{$50.0(\mu \mathrm{g} / \mathrm{ml})$} & \multicolumn{2}{|c|}{$100.0(\mu \mathrm{g} / \mathrm{ml})$} \\
\hline & $\begin{array}{c}\text { Parasite } \\
\text { count }\end{array}$ & $\begin{array}{c}\% \\
\text { Inhibition }\end{array}$ & $\begin{array}{c}\text { Parasite } \\
\text { count }\end{array}$ & \%Inhibition & $\begin{array}{c}\text { Parasite } \\
\text { count }\end{array}$ & \%Inhibition & $\begin{array}{c}\text { Parasite } \\
\text { count }\end{array}$ & \%Inhibition & $\begin{array}{c}\text { Parasite } \\
\text { count }\end{array}$ & $\begin{array}{c}\% \\
\text { Inhibition }\end{array}$ & $\begin{array}{c}\text { Parasite } \\
\text { count }\end{array}$ & $\begin{array}{c}\% \\
\text { Inhibition }\end{array}$ \\
\hline N Control & $230.3 \pm 13.4$ & $0.0 \pm 5.8$ & $230.3 \pm 13.4$ & $0.0 \pm 5.8$ & $230.3 \pm 13.4$ & $0.0 \pm 5.8$ & $230.3 \pm 13.4$ & $0.0 \pm 5.8$ & $230.3 \pm 13.4$ & $0.0 \pm 5.8$ & $230.3 \pm 13.4$ & $0.0 \pm 5.8$ \\
\hline AZA_ETH & $176 . \pm 3.0$ & $23.6 \pm 1.3$ & $146.7 \pm 4.2$ & $36.3 \pm 1.8$ & $83.0 \pm 1.7$ & $64.0 \pm 0.8$ & $36.0 \pm 2.0$ & $84.4 \pm 0.9$ & $14.0 \pm 1.0$ & $93.9 \pm 0.4$ & $0.0 \pm 0.0^{*}$ & $100.0 \pm 0.0$ \\
\hline AZA_AQ & $164 \pm 3.6$ & $28.8 \pm 1.6$ & $142.3 \pm 2.1$ & $38.2 \pm 0.9$ & $71.0 \pm 1.7$ & $69.2 \pm 0.8$ & $32.0 \pm 1.0$ & $86.1 \pm 0.4$ & $11.3 \pm 1.5$ & $95.1 \pm 0.7$ & $0.0 \pm 0.0$ * & $100.0 \pm 0.0$ \\
\hline SEN_ETH & $197.0 \pm 2.0$ & $14.5 \pm 0.9$ & $157.7 \pm 1.5$ & $31.5 \pm 0.7$ & $133.0 \pm 2.0$ & $42.2 \pm 0.9$ & $91.0 \pm 1.0$ & $60.5 \pm 0.4$ & $63.7 \pm 1.5$ & $72.4 \pm 0.7$ & $2.0 \pm 2.0 *$ & $99.1 \pm 0.9$ \\
\hline SEN_AQ & $206.0 \pm 2.0$ & $10.6 \pm 0.9$ & $168.0 \pm 1.0$ & $27.1 \pm 0.4$ & $143.0 \pm 2.0$ & $37.9 \pm 0.9$ & $102.0 \pm 4.4$ & $55.7 \pm 2.0$ & $73.3 \pm 1.5$ & $68.2 \pm 0.7$ & $4.0 \pm 2.0$ & $98.3 \pm 0.9$ \\
\hline MOR_ETH & $215.0 \pm 3.0$ & $6.6 \pm 1.3$ & $178.0 \pm 2.0$ & $22.7 \pm 0.9$ & $154.0 \pm 1.7$ & $33.1 \pm 0.8$ & $97.0 \pm 1.0$ & $57.9 \pm 0.4$ & $55.7 \pm 1.5$ & $75.8 \pm 0.7$ & $39.0 \pm 1.0$ & $83.1 \pm 0.4$ \\
\hline MOR_AQ & $224.0 \pm 1.0$ & $2.7 \pm 0.4$ & $186.3 \pm 2.1$ & $19.1 \pm 0.9$ & $168.0 \pm 4.0$ & $27.1 \pm 1.7$ & $122.7 \pm 2.5$ & $46.7 \pm 1.1$ & $109.0 \pm 3.0$ & $52.7 \pm 1.3$ & $57.0 \pm 0.0$ & $75.2 \pm 0.0$ \\
\hline MAG_ETH & $208.0 \pm 1.0$ & $9.7 \pm 0.4$ & $172.0 \pm 1.0$ & $25.3 \pm 0.4$ & $156.7 \pm 2.1$ & $32.0 \pm 0.9$ & $92.0 \pm 2.0$ & $60.1 \pm 0.9$ & $59.0 \pm 1.0$ & $74.4 \pm 0.4$ & $23.3 \pm 2.1$ & $89.9 \pm 0.9$ \\
\hline MAG_AQ & $213.0 \pm 2.0$ & $7.5 \pm 0.9$ & $179.0 \pm 3.0$ & $22.3 \pm 1.3$ & $162.0 \pm 2.0$ & $29.7 \pm 0.9$ & $114.7 \pm 2.5$ & $50.2 \pm 1.1$ & $76.0 \pm 4.0$ & $67.0 \pm 1.7$ & $43.0 \pm 2.0$ & $81.3 \pm 0.9$ \\
\hline $\mathrm{CQC}$ & $20.3 \pm 1.5 \mathrm{C}$ & $91.2 \pm 0.7$ & $16.7 \pm 1.5 \mathrm{C}$ & $92.8 \pm 0.7$ & $9.0 \pm 2.0 \mathrm{C}$ & $96.1 \pm 0.9$ & $2.7 \pm 1.2 \mathrm{C}$ & $98.8 \pm 0.5$ & $0.7 \pm 1.2 \mathrm{C}$ & $99.7 \pm 0.5$ & $0.0 \pm 0.0 \mathrm{C}$ & $100.0 \pm 0.0$ \\
\hline
\end{tabular}

$\mathrm{SD}=$ standard deviation; \% Inh. = percentage parasite inhibition; * statistically the same antimalarial activity with control (CQ) using one-way ANOVA post hoc (donnet) at $\mathrm{p}<0.05$, others had statistically significant lower antimalarial activity with the control $(\mathrm{CQ}) ; \mathrm{C}=\mathrm{control}$;

(CQ) $\mathrm{C}=$ control, $\mathrm{N}$ control= Negative control, AZA_ETH=Azadirachta indica ethanol, AZA_ETH=Azadirachta indica Aqueous, SEN_ETH=Cassia occidentalis Ethanol,

SEN_AQ=Cassia occidentalis Aqueous, MOR AQ= Moringa oleifera Aqueous, MO ETH= Moringa oleifera Ethanol, MAG_AQ=Mangifera indica Aqueous,

MAG_ETH=Mangifera indica Ethanol 


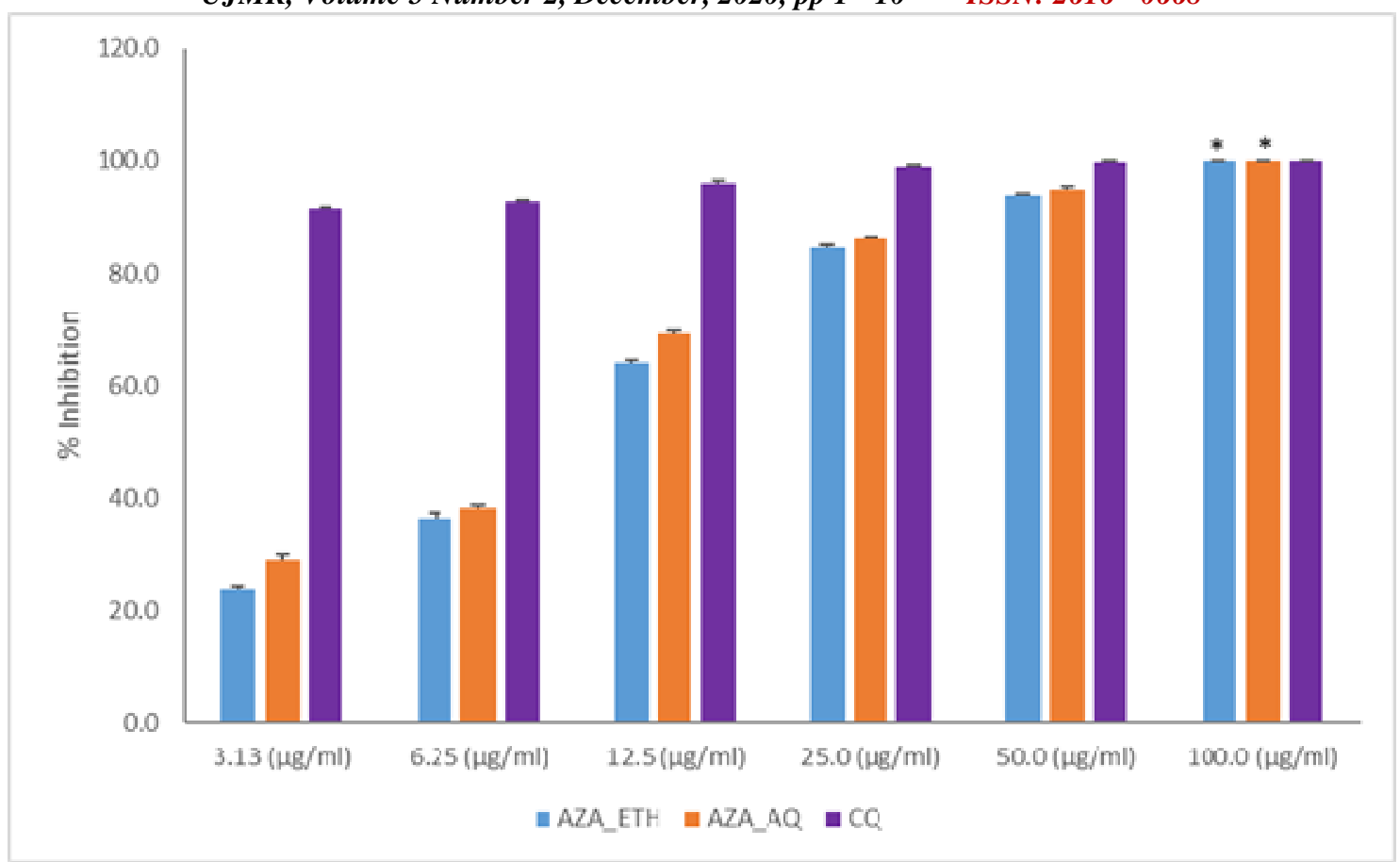

Figure1: Antimalarial activity of Aqueous and Ethanol extracts of Azadirachta indica

* = Statistically the same antimalarial activity with chloroquine

AZA_ETH=Azadirachta indica ethanol

AZA_ETH=Azadirachta indica Aqueous

$\mathrm{CQ}=$ Control (Chloroquine)

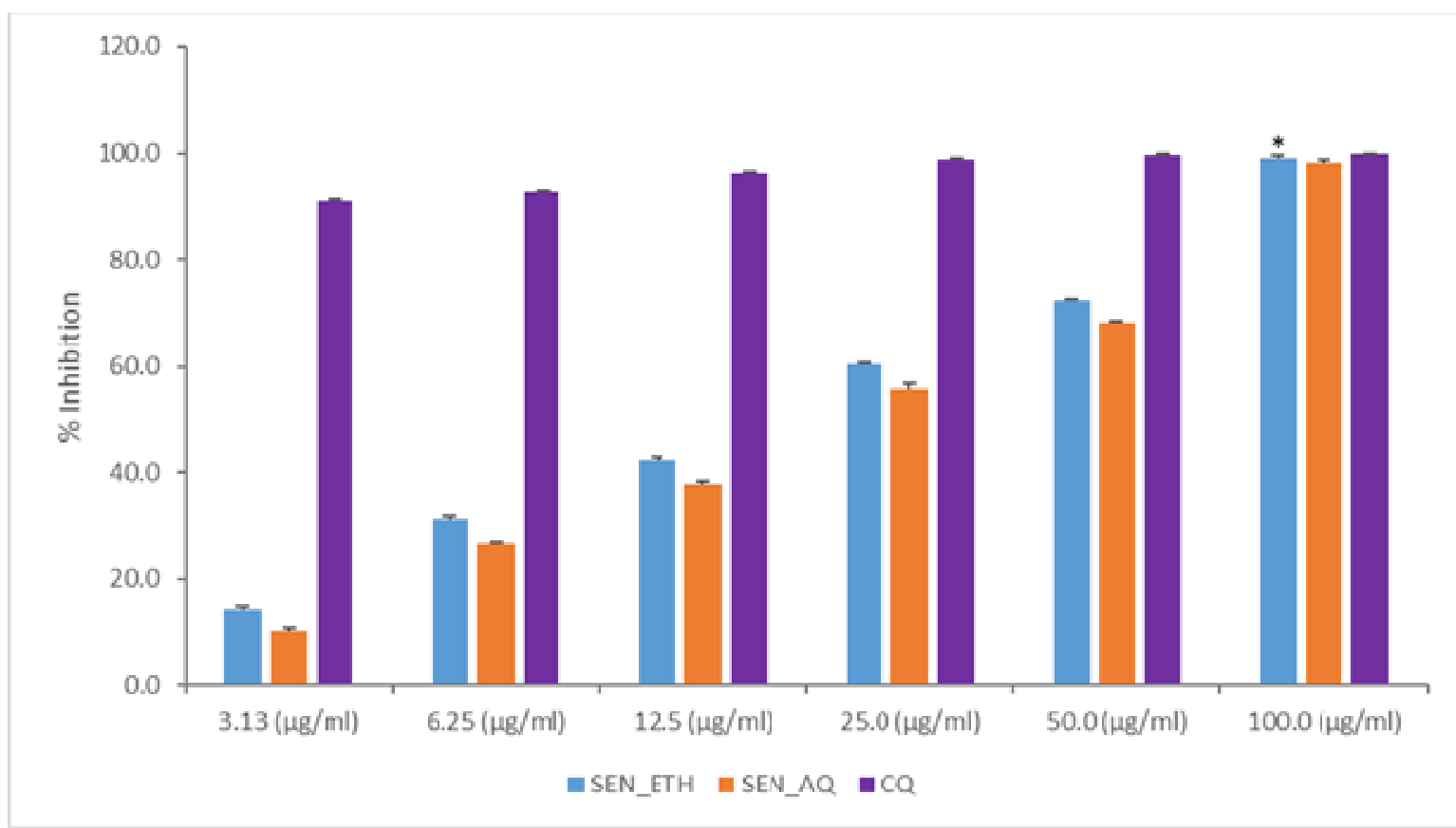

Figure2: Antimalarial activity of Aqueous and Ethanol extracts of Cassia occidentalis

* = Statistically the same antimalarial activity with chloroquine, SEN_ETH=Cassia occidentalis Ethanol, SEN_AQ=Cassia occidentalis Aqueous, $\mathrm{CQ}=$ Control (Chloroquine) 


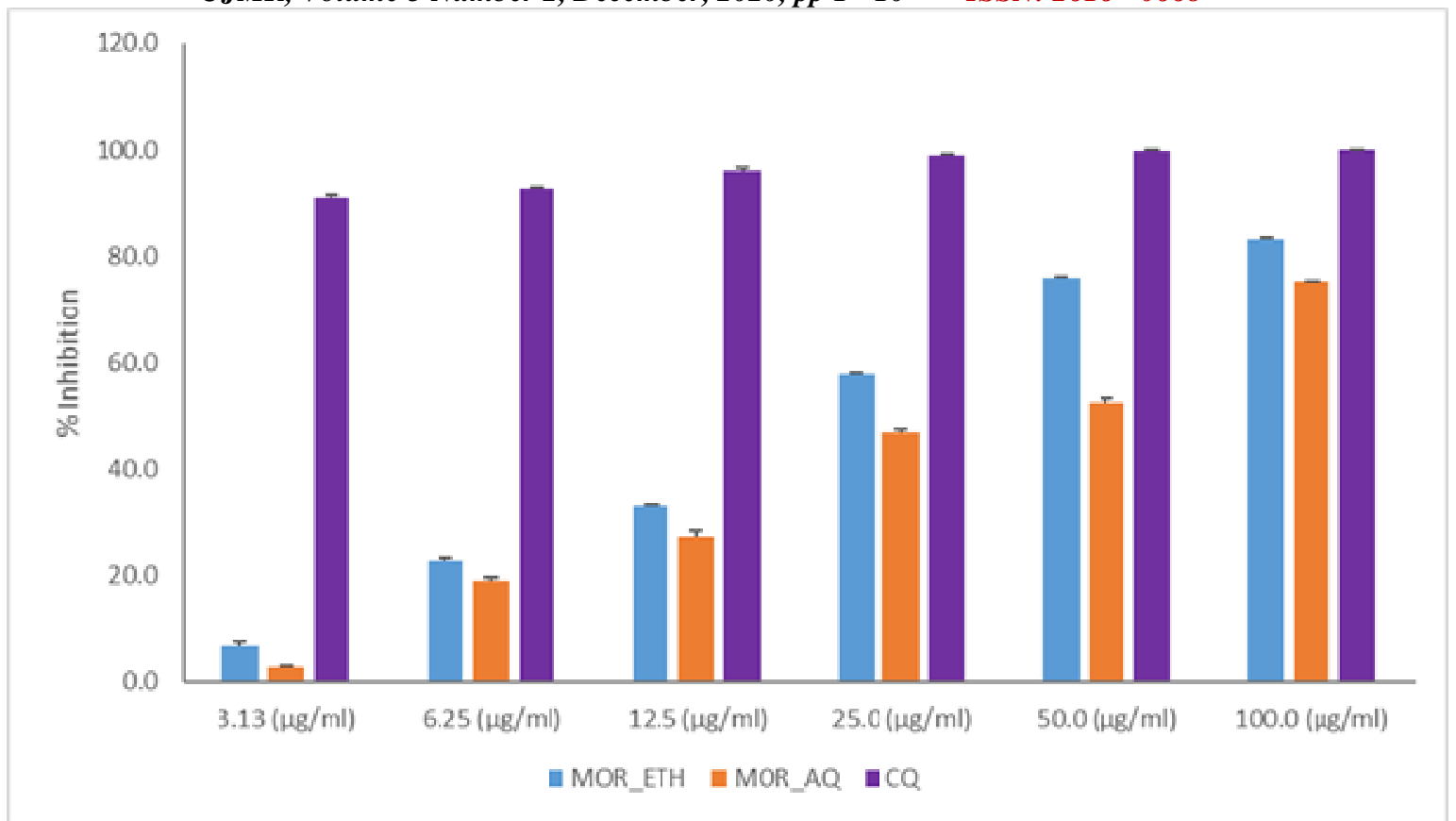

Figure 3: Antimalarial activity of Aqueous and Ethanol extracts of Moringa oleifera MOR AQ $=$ Moringa oleifer $a$ Aqueous, MO_ETH= Moringa oleifer $a$ Ethanol, $\mathrm{CQ}=$ Control (Chloroquine)

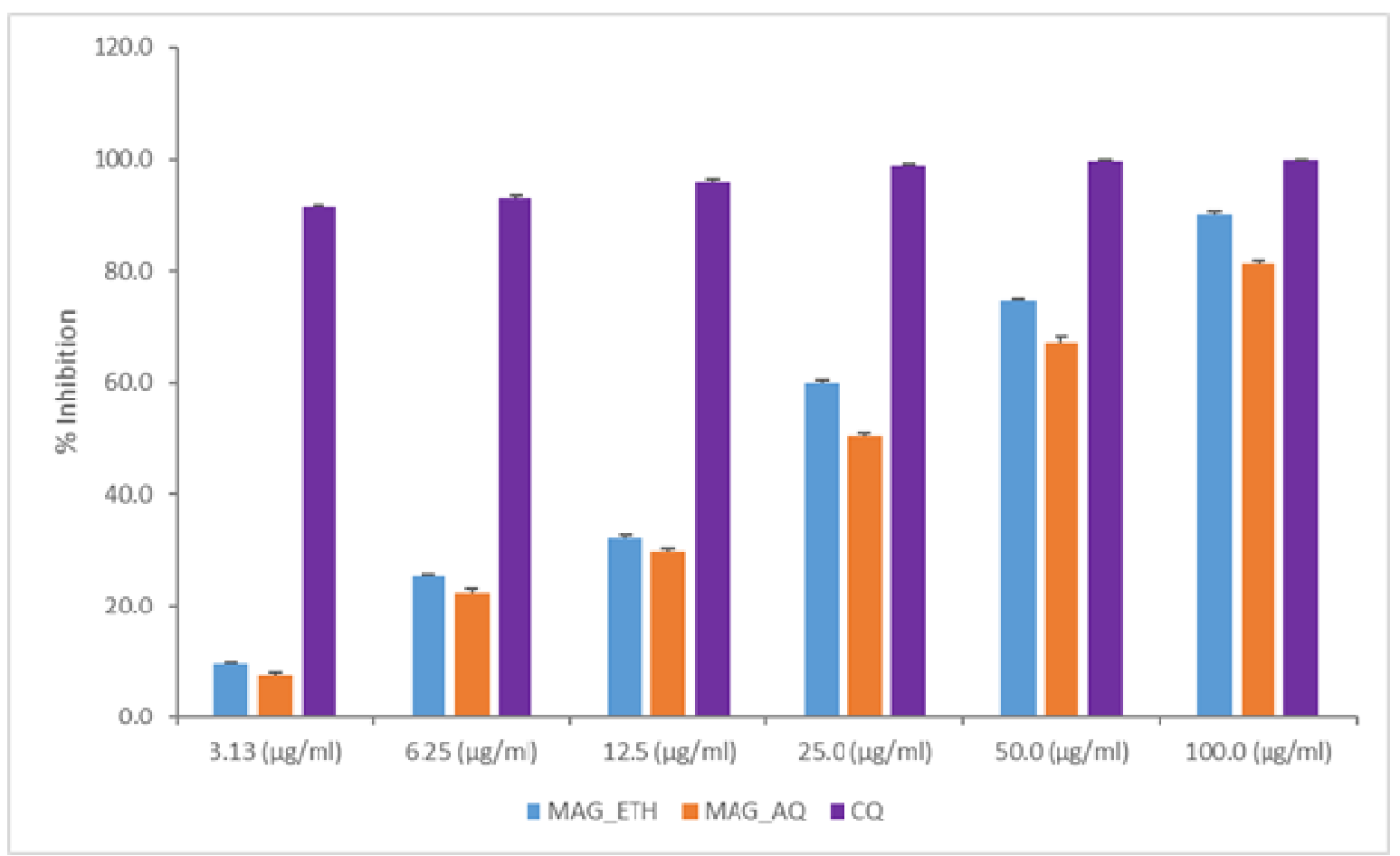

Figure 4: Antimalarial activity of Aqueous and Ethanol extracts of Mangifera indica $M A G \_A Q=$ Mangifera indica Aqueous, MAG_ETH=Mangifera indica Ethanol, $\mathrm{CQ}=$ Control (Chloroquine) 
UJMR, Volume 5 Number 2, December, 2020, pp 1 - $10 \quad$ ISSN: 2616 - 0668

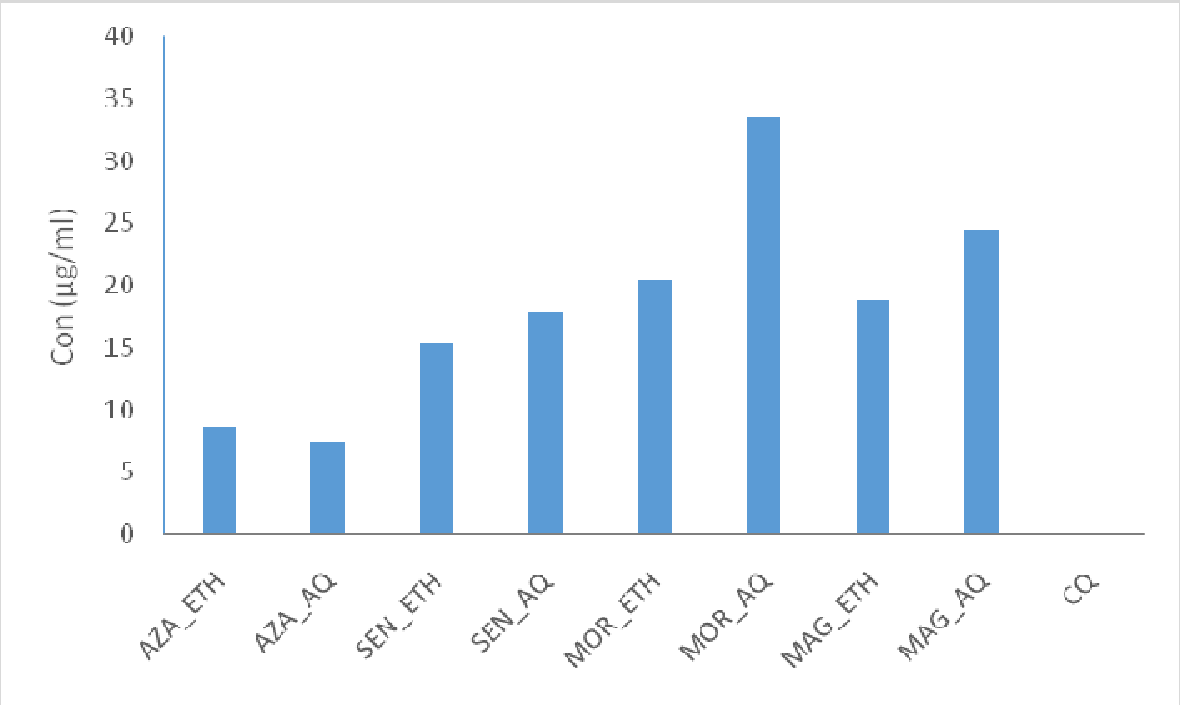

Figure 5: Median inhibitory Concentration of plant Extracts

AZA_ETH=Azadirachta indica ethanol, AZA_ETH=Azadirachta indica Aqueous, SEN_ETH=Cassia occidentalis Ethanol, SEN_AQ=Cassia occidentalis Aqueous, $\mathrm{MOR} A \mathrm{Q}=$ Moringa oleifera Aqueous, MO_ETH= Moringa oleifera Ethanol, MAG_AQ=Mangifera indica Aqueous, MAG_ETH=Mangifera indica Ethanol, CQ= Control (Chloroquine)

Table 2: Phytochemicals in Plant extract

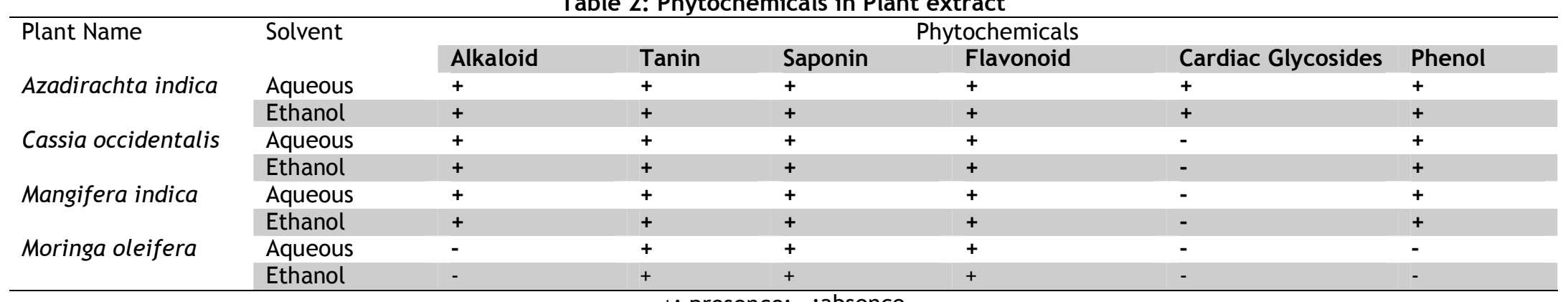

+: presence; -:absence 


\section{UJMR, Volume 5 Number 2, December, 2020, pp 1 - 10 ISSN: 2616 - 0668}

\section{DISCUSSION}

The result of antiplasmodial activity of plant extracts shows that Aqueous and ethanol extract of $A$. indica is the most effective against schizonts growth of $P$. falciparum followed by $S$. occidentalis, $M$. indica ethanol extract, $M$. Oleifera ethanol extract and then $M$. indica aqueous extract and $M$. Oleifera aqueous extract which demonstrated least antimalarial activity. Azadirachta indica and Cassia occidentalis both demonstrate complete schizont growth inhibition when $P$. falciparum is treated with $100 \mu \mathrm{g} / \mathrm{ml}$ concentration and there was no statistical significant difference in their result when compared with the positive control using one-way ANOVA post hoc (donnet) at significance level of $p<0.05$ while other plant extract gave a statistical significant difference when compare with the positive control (Chloroquine). Antimalarial activity can be classified into four broad categories according to previous studies which are; extract with IC 50 less than $10 \mu \mathrm{g} / \mathrm{ml}$ is considered very good; 10 to $50 \mu \mathrm{g} / \mathrm{ml}$ considered moderate. over $50 \mu \mathrm{g} / \mathrm{ml}$ considered to have low activity and greater than $100 \mu \mathrm{g} / \mathrm{ml}$ are considered inactive (Cudjoe, Donu, Okonu, Amponsah, and Amoah, 2020; Sha, 2011).Aqueous extract of $A$. indica leaves extract significantly inhibit the schizont growth with IC $50=7.39$ $\mu \mathrm{g} / \mathrm{ml}$. The antimalarial activity of $A$. indica was previously reported by (Alshawsh et al.,2009). They found that the aqueous extract of $A$. indica leaves showed IC50 value $2.0 \mu \mathrm{g} / \mathrm{ml}$ which is less than $10 \mu \mathrm{g} / \mathrm{ml}$ which is in agreement with this study (IC50=7.39 $\mu \mathrm{g} / \mathrm{ml})$. Also, the ethanolic extract showed very good activity with IC50 $=8.63 \mu \mathrm{g} / \mathrm{ml}$. The anti-plasmodial activity of the leaves of Moringa oleifera has been reported by Donkor et al., 2015 against $P$. falciparum and their findings showed moderate antimalarial activity which is in agreement with this study. In this study, the result of antiplasmodial activity of Moringa oleifera gave an IC50 of $33.53 \mu \mathrm{g} / \mathrm{ml}$ for the ethanolic extract and $20.50 \mu \mathrm{g} / \mathrm{ml}$ for the aqueous extract. Tarkang et al., 2014 reported the antiplasmodial activity of Mangifera indica with a different experimental method. The result of their ethanolic extract is in agreement with this study which gave 18.80 within the range of moderate antimalarial activity but the result of their aqueous extract is in contrast with this study. Their aqueous extract gave a low antiplasmodial activity while the result of this study demonstrate moderate antiplasmodial activity. Based on the classification of antiplasmodial activity reported in previous studies, result from this study of the water and ethanol extracts of Azadirachta indica with IC50 less than $10 \mu \mathrm{g} / \mathrm{ml}$ have very good antimalarial activity while Cassia occidentalis, Mangifera indica and Moringa oleifera with IC50 range between $15.30 \mu \mathrm{g} / \mathrm{ml}$ to $33.5 \mu \mathrm{g} / \mathrm{ml}$ can be said to have moderate antimalarial activity which is in agreement with previous studies by Alkali et al.,(2018); Tarkang et al.,(2014).

The phytochemical screening of medicinal plants showed the presence of tannins, saponins, alkaloids, flavonoid, phenol and cardiac glycosides in the extracts, which may be responsible for the antiplasmodial activity. Alkali et al.,(2018) also reported the presence of saponins, flavonoids, alkaloids, terpenes, anthraquinones, glycoside and balsam in $S$. occidentalis and $A$. indica. Bioactive compound in these plants have reported to for various medicinal purpose and may also be responsible for the antiplasmodial activity of these plants. The presence of triterpenoids, limonoids, in $A$. indica may take part in the antimalarial activity of this traditional medicinal herb. It is known that the limonoid gedunin, isolated from $A$. indica, exerts antimalarial effect in vitro (Alshawsh et al., 2009). Flavonoids and phenolic compounds in herbal plants have also been associated with antimalarial activity and difference in the antimalarial activity. Plants with higher level of these compounds may exhibit higher antimalarial activity than others.

\section{CONCLUSION}

All plant extracts showed dose dependent antimalarial activities and the study affirmed that selected plants (Cassia occidentalis, Azadiracta indica, Moringa oleifera and Magnifera indica)have great potentials to cure Malaria and justifies the reliance of indigenous rural communities on traditional health care system. The phytochemical screening revealed the presence of bioactive constituents that could be the reason for pharmacological activity. The selected plants for this study can be said to be future promising for the treatment of malaria. However, in vivo studies on these medicinal plants are necessary and should seek to determine toxicity of the active constituents, their side effects. 
REFERENCES

Alkali, K., Abdullahi, K., Mshelia, H., Yahaya, M., N Abubakar, and Tarbutu, A. (2018). In Vitro Antiplasmodial Activity of Aqueous Leaves Extract of Azadirachta indica (Juss), Senna occidentalis (Linn) against Combination Therapy of Both Plants Extract on the Multiplication of Plasmodium Falciparum (Laveran). Annals of Advanced Biomedical Sciences, 1(1): 1-6.

Alshawsh, A. M., Mothana, R. A., Al-shamahy Hassan, A., Alsllami, S. F., and Lindequist, U. (2009). Assessment of Antimalarial Activity against Plasmodium Falciparum and Phytochemical Screening of Some Yemeni Medicinal Plants. Evidence-Based Complementary and Alternative Medicine, 6(4): 453-456.

Cudjoe, E., Donu, D., Okonu, R. E., Amponsah, J. A., and Amoah, L. E. (2020). The in Vitro Antiplasmodial Activities of Aqueous Extracts of Selected Ghanaian Herbal Plants. Journal of Parasitology Research, 2020(5041919):1-8.

Donkor, A., Oduro-mensah, D., Ani, E., Ankamah, E., Nsiah, S., and Dickson, E. K. (2015). In vitro Anti-Plasmodial Activity of Aqueous and Ethanolic Extracts of Moringa oleifera and Phyllanthus amarus. International Journal of Biological Chemistry, 9(4):198206.

FMOH. (2015). National malaria and vector control division. In national guidelines for diagnosis and treatment of malaria Third edition. Abuja. Accessed on 4/05/2019 from http;//www.nmcp.gov.ng/.

Greenwoodv D, Barer M, Slack R, I. W. (2012). Medical Microbiology (18th ed.). China.

Lamb TJ. (2012). Immunity to Parasitic Infection (1st ed.). New Delhi India: Wiley-Blackwell.

Liadi, Y. M., Abdulhamid, A., Umar, L., and I Usman, A. (2016). Ethnobotanical Survey of Indigenous Plants used in the Treatment of Malaria in Dutsin-Ma Metropolitan Area of Katsina State. Katsina Journal of Natural and Applied Sciences, 5(1): 183-189.

Mehta, D., and N. Desai. (2013). Laboratory Diagnosis of Malaria- Various Method and its Comparison. National Journal of Integrated Research in Medicine, 4(3): 138-143.

NMEP, (2016). Nigeria Malaria Indicator Survey. Abuja, Nigeria. Accessed on September 18, 2019 from https://health.gov.ng

Oladepo, O., Oyeyemi, A. S., Titiloye, M. A.,
Adeyemi, A. O., Burnett, S. M., Apera, I., ... Alliu, M. (2019). Malaria testing and treatment knowledge among selected rural patent and proprietary medicine vendors( PPMV) in Nigeria. Malaria Journal, 18(103): 1-8.

Sha, A. (2011). In Vitro Antimalarial Activity of the Extracts of Vernonia amygdalina Commonly used in Traditional Medicine in Nigeria. Science World Journal, 6(2), 5-9.

Singh, Sarman. (2011). Current scenario of control of malaria. Journal of Tropical Parasitology, 1(2): 52-54.

Sofowora, A. (1993). Medicinal plants and Traditional Medicine in Africa (2nd edition). Ibadan, Nigeria: spectrum Book Limited.

Tarkang, P. A., Franzoi, K. D., Lee, S., Lee, E., Vivarelli, D., Freitas-junior, L., ... Guantai, A. N. (2014). In Vitro Antiplasmodial Activities and Synergistic Combinations of Differential Solvent Extracts of the Polyherbal Product, Nefang. Biomedical Research International, 2014(835013): 110.

Trager, W., \& Jensen, J. B. (1976). Human malaria parasites in continuous culture. Science, 193, 673-675.

Trease, G., and Evans, W. (1989). Pharmacognosy (13th Editi). London: Bailliere Tindall.

Umar, H., Umar, I., and Ibrahim, A. (2017). Phytochemical Analysis and In-vitro Anti Plasmodia Activity of Chrozophora Senegalensis Extracts on Plasmodium Falciparum. Nigerian Journal of Chemical Research, 22(2): 61-71.

Uzochukwu, B. S. C., and Emma-ukaegbu, O. P. E. U. (2010). Malaria Treatment Services in Nigeria: A Review. Nigerian Medical Journal, 51(3): 114-119.

WHO. (2001). In vitro micro test (MarkIII) for the assessment of the response of Plasmodium Falciparum to chloroquine, mefloquine, quinine, amodiaquine, sulfadoxine/pyrimethamine and artemisinin. Geneva

WHO. (2015). Guidelines For the treatment of malaria (Third). World Health Organization.

WHO. (2017). World malaria report. In World malaria report. Geneva, Switzerland. Retrieved from https://apps.who.int/iris/handle/10665/27 5867. 